\title{
Comparative activity of ertapenem and piperacillin-tazobactam in a murine systemic infection model with Bacteroides fragilis and Escherichia coli
}

It is now well-recognized that most intra-abdominal infections involve multiple types of bacteria. The most frequently encountered organisms in intra-abdominal infections are Escherichia coli and Bacteroides fragilis. These two micro-organisms are indigenous components of faecal microbiota, but can cause intra-abdominal abscess following surgery (Goldstein \& Snydman, 2004). Therefore, an effective antimicrobial agent for the treatment of intra-abdominal infections requires a broad spectrum of activity against both aerobic and anaerobic bacteria.

Ertapenem is a new carbapenem with a broad spectrum of activity against Gram-negative pathogens, including extended-spectrum- $\beta$-lactamase and AmpC-producing Enterobacteriaceae, as well as against Gram-positive aerobic and anaerobic pathogens (Goldstein \& Snydman, 2004; Wexler, 2004). Clinical trials involving complicated intraabdominal infections demonstrated that ertapenem has equivalent efficacy and safety when compared with piperacillin-tazobactam (Solomkin et al., 2003; Dela Pena et al., 2006). However, in the setting of mixed infections,

antimicrobial therapy may result in clinical improvement and a decrease in bacterial burden without, necessarily, eradicating the infection. There are no in vivo time-kill studies regarding ertapenem and piperacillin-tazobactam pharmacodynamics. Thereby, in the present study, we compared the in vivo activity of ertapenem with that of the piperacillin-tazobactam combination in a murine systemic mixed infection model.

A piperacillin-tazobactam preparation (Tazocin; Lederle Piperacillin) and ertapenem sodium (Invanz; Merck Sharp \& Dohme) were purchased commercially and solubilized in sterile saline $(0.9 \%$ $\mathrm{NaCl})$ for injection. For MIC determinations, ertapenem sodium was kindly provided as standard powder by Merck Sharp \& Dohme. B. fragilis (ATCC 25285) and E. coli (ATCC 25922) were used throughout the experiments. The obligate anaerobe $B$. fragilis was incubated anaerobically at $37{ }^{\circ} \mathrm{C}$ in an anaerobic chamber (Forma Scientific) containing an atmosphere of $85 \% \mathrm{~N}_{2}, 10 \% \mathrm{H}_{2}$ and $5 \%$ $\mathrm{CO}_{2}$, and the facultative anaerobe E. coli was incubated aerobically or anaerobically at $37{ }^{\circ} \mathrm{C}$.

MICs of the test drugs were determined before and after antimicrobial therapy by the agar dilution method, according to the recommendations of the Clinical Laboratory Standards Institute (formerly the National Committee for Clinical Laboratory Standards) (NCCLS, 2003, 2004).

All experimental procedures with animals were approved by the ethics committee in animal experimentation of the Universidade Federal de Minas Gerais (CETEA/UFMG). Female Swiss mice (Animal Care Center, Universidade Federal de Minas Gerais, Brazil), 3 weeks old and weighing 15 to $18 \mathrm{~g}$, were inoculated intraperitoneally with $0.1 \mathrm{ml}$ of a mixed culture containing about $10^{7}$ c.f.u. of each bacteria per mouse. The bacterial inoculum was prepared by suspending overnight cultures of $B$. fragilis and E. coli in $3 \%$ porcine gastric mucin (Sigma-Aldrich), which were then mixed together in a volume ratio of $1: 1$.

In pharmacokinetic studies, infected mice were treated $3 \mathrm{~h}$ after bacterial challenge with a single subcutaneous (sc) injection of either ertapenem $\left(25 \mathrm{mg} \mathrm{kg}^{-1}\right)$ or piperacillin-tazobactam $\left(340 \mathrm{mg} \mathrm{kg}^{-1}\right)$. The concentration of antibiotics used was extrapolated from the human equivalent dose as described by Freireich et al. (1966). Blood samples were collected using cardiac puncture at $0.25,0.5,1,2,3$ and $6 \mathrm{~h}$ post-injection ( $n=4$ per group). Blood samples were processed to plasma by centrifugation $\left(3000 \mathrm{~g}, 10 \mathrm{~min}, 4{ }^{\circ} \mathrm{C}\right)$ and stored at $-80{ }^{\circ} \mathrm{C}$ until needed for analysis. Antibiotic concentrations were determined in quadruplicate by an agar diffusion bioassay (Chapin-Robertson \& Edberg, 1991). E. coli ATCC 25922 was used as the indicator organism for both drugs. Standard curves were determined using mouse plasma. Zones of inhibition were measured to the nearest $0.01 \mathrm{~mm}$ by a digital caliper (digimatic caliper; Mitutoyo). The linearity of the standard curves was assessed with a regression coefficient of $\geqslant 0.995$, and intra-plate and inter-plate variations were $\leqslant 11 \%$. The limits of detection of the assay were $0.12 \mu \mathrm{g}$ ertapenem $\mathrm{ml}^{-1}$ and $4 \mu \mathrm{g}$ piperacillin-tazobactam $\mathrm{ml}^{-1}$.

For bacterial titre studies, infected animals were administered four doses of ertapenem (25 $\mathrm{mg} \mathrm{kg}^{-1}$, sc) or piperacillin-tazobactam $\left(340 \mathrm{mg} \mathrm{kg}^{-1}, \mathrm{sc}\right)$ at $6 \mathrm{~h}$ intervals, starting $3 \mathrm{~h}$ after infection. A separate group of control animals received saline $(0.9 \% \mathrm{NaCl})$ following the same schedule as for mice treated with antibiotics. Just prior to antibiotic initiation, and at 3, 6, 9 and $21 \mathrm{~h}$ after the first injection, groups $(n=4)$ of control and drug-treated animals were sacrificed by cervical dislocation. Subsequently, samples of blood and peritoneal fluid from each animal were harvested. In all specimens collected, bacterial counts were determined by performing a $1: 10$ serial dilution in sterile PBS and then $0.1 \mathrm{ml}$ aliquots of each dilution were plated onto selective medium: MacConkey agar (Difco) for E. coli and Bacteroides bile aesculin agar for $B$. fragilis. Viable colonies of $E$. coli were counted after overnight incubation at $37{ }^{\circ} \mathrm{C}$, and $B$. fragilis colonies were counted after incubation for $48 \mathrm{~h}$ at $37{ }^{\circ} \mathrm{C}$ in an anaerobic chamber. Dilutions were performed to eliminate potential 
Table 1. Pharmacodynamic parameters of ertapenem and piperacillin-tazobactam

\begin{tabular}{|lccc|}
\hline Antibiotic & \multicolumn{2}{c}{$\operatorname{MIC}^{\star}\left(\mu \mathrm{g} \mathrm{ml}^{-1}\right)$ for: } & $\begin{array}{c}\text { \% } \boldsymbol{t}>\text { MIC in } \\
\text { infected mice }\end{array}$ \\
\cline { 2 - 4 } & E. coli ATCC 25922 & B. fragilis ATCC 25285 & \\
\hline Ertapenem $\dagger$ & 0.016 & 0.12 & 100 \\
Piperacillin-tazobactam $\ddagger$ & $2.0-0.25$ & $0.5-0.06$ & 46 \\
\hline
\end{tabular}

${ }^{*} \mathrm{MIC}$ values determined before and after the antimicrobial therapy are the same.

$\dagger$ Susceptibility breakpoints for ertapenem: B. fragilis $\leqslant 4.0 \mu \mathrm{g} \mathrm{ml} l^{-1}$ and E. coli $\leqslant 2.0 \mu \mathrm{g} \mathrm{ml}^{-1}$. $\ddagger$ Susceptibility breakpoints for piperacillin-tazobactam: B. fragilis $\leqslant 32.0 / 4.0 \mu \mathrm{g} \mathrm{ml}^{-1}$ and $E$. coli $\leqslant 16.0 / 4.0 \mu \mathrm{g} \mathrm{ml}^{-1}$. carryover effects. The limit of quantification was 300 c.f.u. $\mathrm{ml}^{-1}$.

For each drug studied, analysis of variance (two-way ANOVA) was used to compare the effects between the different groups, followed by use of the Holm-Sidak method to compare treated and untreated groups two by two. $P$ values of $<0.05$ were considered significant. piperacillin-tazobactam for E. coli ATCC 25922 and B. fragilis ATCC 25285 are summarized in Table 1. No change in drug susceptibility was observed among any of the post-therapy bacterial samples.

Following the first $6 \mathrm{~h} \mathrm{sc}$ administration into infected mice, ertapenem $(25 \mathrm{mg}$ $\left.\mathrm{kg}^{-1}\right)$ and piperacillin-tazobactam $\left(340 \mathrm{mg} \mathrm{kg}{ }^{-1}\right.$ ) had $C_{\max }$ values of 117.9 and $179.8 \mu \mathrm{g} \mathrm{ml}^{-1}$ and half-lives of 1.0 and $0.5 \mathrm{~h}$, respectively. The projected exposures for a single dose of ertapenem
The MICs of ertapenem and and piperacillin-tazobactam in comparison with human exposures to both antibiotics are shown in Table 2. The time proportions of the dosing interval where the plasma concentration exceeded the MIC (\% $t>$ MIC) were 100 and $46 \%$ for ertapenem and piperacillin-tazobactam, respectively (Table 1 ).

The pre-treatment E. coli counts were 6.7 and $6.1 \log _{10}$ c.f.u. $\mathrm{ml}^{-1}$ in the peritoneal fluid and blood, respectively. Analysis of the kill curves for peritoneal fluid and blood revealed that ertapenem exhibited significantly higher killing activity than piperacillin-tazobactam $(P<0.05$, two-way ANOVA) (Fig. 1a, b). Until $6 \mathrm{~h}$ after the first dose, the E. coli counts in the peritoneal fluid and blood were similar for both treatments $(P>0.05)$. However, at $9 \mathrm{~h}$ after the first dose, the E. coli counts in the peritoneal fluid and blood were reduced to a higher extent by ertapenem $\left(-3.8\right.$ and $-4.2 \log _{10}$ c.f.u. $\mathrm{ml}^{-1}$,
Table 2. Comparative pharmacokinetic parameters of ertapenem and piperacillintazobactam in humans and infected mice serum

Results are presented as the mean $( \pm \mathrm{SD})$ concentration with 4 animals for each test.

\begin{tabular}{|c|c|c|c|c|}
\hline & \multicolumn{2}{|c|}{ Ertapenem } & \multicolumn{2}{|c|}{ Piperacillin-tazobactam } \\
\hline & Mouse & Human ${ }^{\star}$ & Mouse & Human $\dagger$ \\
\hline Dose & $\begin{array}{l}25 \mathrm{mg} \mathrm{kg}^{-1} \mathrm{sc} \\
\text { four doses } \neq\end{array}$ & $1.0 \mathrm{~g}$ iv once daily & $\begin{array}{l}340 \mathrm{mg} \mathrm{kg}^{-1} \mathrm{sc}, \\
\text { four doses } \ddagger\end{array}$ & $\begin{array}{l}3.375 \mathrm{~g} \text { iv, every } \\
6 \mathrm{~h}\end{array}$ \\
\hline$C_{\max }\left(\mu \mathrm{g} \mathrm{ml}^{-1}\right)$ & $117.9 \pm 19.5$ & $154.9 \pm 22.0$ & $179.8 \pm 23.6$ & $122.22 \pm 30.37$ \\
\hline$t 1 / 2(\mathrm{~h})$ & 1.0 & 3.8 & 0.5 & 1.24 \\
\hline
\end{tabular}

iv, Intravenous.

${ }^{\star}$ Data from Majumdar et al. (2002).

$\dagger$ Data from Li et al. (2005).

$\ddagger$ Total dose of $100 \mathrm{mg} \mathrm{kg}^{-1} \mathrm{day}^{-1}$ and $1.35 \mathrm{~g} \mathrm{~kg}^{-1} \mathrm{day}^{-1}$ for ertapenem and piperacillintazobactam, respectively. respectively) compared with piperacillin-tazobactam $(-1.5$ and -1.8 $\log _{10}$ c.f.u. $\mathrm{ml}^{-1}$, respectively). Ertapenem produced sustained suppression of counts, and eventually resolved the infection in the peritoneal fluid and blood by 21 and $9 \mathrm{~h}$, respectively.

The pre-treatment $B$. fragilis counts were 4.6 and $4.1 \log _{10}$ c.f.u. $\mathrm{ml}^{-1}$ in the peritoneal fluid and blood, respectively. Analysis of the kill curves revealed that both drugs resolved the infection in the blood and peritoneal fluid by 3 and $6 \mathrm{~h}$, respectively, although ertapenem exhibited significantly higher killing activity than piperacillin-tazobactam in the peritoneal fluid ( $P<0.05$, two-way ANOVA) (Fig. 1c, d). Nine hours after the first dose, the $B$. fragilis counts in the peritoneal fluid and blood were reduced by ertapenem to -3.7 and $-2.6 \log _{10}$ c.f.u. $\mathrm{ml}^{-1}$, respectively. At the same time, piperacillin-tazobactam reduced the $B$. fragilis counts in the peritoneal fluid and blood to -2.3 and $-1.8 \log _{10}$ c.f.u. $\mathrm{ml}^{-1}$, respectively.

In the therapeutic concentration range, ertapenem is highly bound to plasma protein (95\%) and this phenomenon probably contributes to its long plasma half-life (Majumdar et al., 2002). The main pharmacokinetic-pharmacodynamic parameter of carbapenems and penicillins, which are antibiotics with time-dependent killing activities, is the $\% t>\mathrm{MIC}$ (Nix et al., 2004). In the present model of systemic infection, the superior activity of ertapenem, mainly against $E$. coli, can be attributed, at least in part, to its longer plasma half-life in mice (resulting in a longer \% $t>\mathrm{MIC}$ ) when compared to piperacillin-tazobactam (Tables 1 and 2).

Both drugs exhibited similar activity against $B$. fragilis, probably due to a lower inoculum $\left(\sim 4.7 \log _{10}\right.$ c.f.u. $\left.\mathrm{ml}^{-1}\right)$ detected just prior to the first dose. The influence of inoculum size of E. coli and B. fragilis on piperacillin-tazobactam activity has been described in other studies (Goldstein et al., 1991; König et al., 1998; Stearne et al., 2004). König et al. (1998) demonstrated that piperacillin activity was diminished at least 128-fold when high inocula of E. coli ATCC 25922 were used. In a recent in vitro study we also demonstrated a bacteriostatic activity of 
(a)

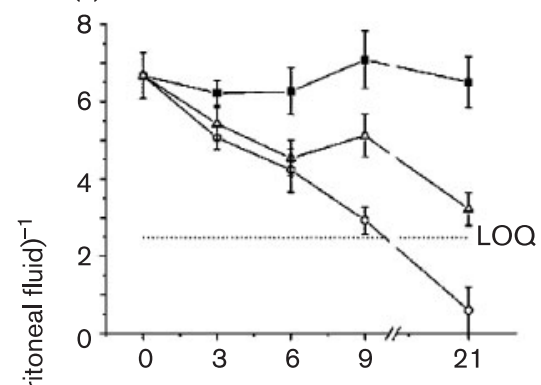

(c)

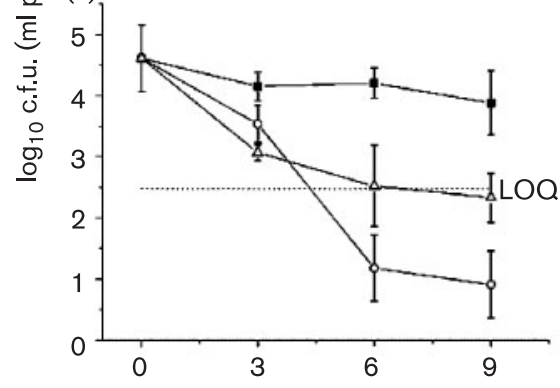

Time (h)

Fig. 1. Effect of ertapenem $(\bigcirc)$ and piperacillin-tazobactam $(\triangle)$ on peritoneal fluid $(a, c)$ and blood $(b, d)$ bacterial counts in the murine systemic mixed infection model. $(a, b) E$. coli counts; (c, d) B. fragilis counts. $n=4$ for all groups at all time points. Data represent the means $\pm S D$. LOQ, Limit of quantification. $\mathbf{\square}$, Control.

piperacillin-tazobactam against high inocula of E. coli ATCC 25922, as well as an increase in MIC (Santos et al., 2007). Thus, this inoculum effect can be an alternative explanation for the higher activity of ertapenem against $E$. coli (starting inoculum of $\sim 6.4 \log _{10}$ c.f.u. $\mathrm{ml}^{-1}$ ) compared with

piperacillin-tazobactam. A caveat of the present study is that single strains of $B$. fragilis and E. coli were examined, and it remains to be determined whether the findings of this investigation extend to other strains.

In conclusion, the data from the present study demonstrated that although both drugs have been effective in the treatment of this model of mixed infection, ertapenem exhibited a higher activity against E. coli relative to piperacillintazobactam, in agreement with a previous time-kill study in vitro (Santos et al., 2007).

\section{Acknowledgements}

The study was supported by grants from Conselho Nacional de Desenvolvimento
Científico e Tecnológico (CNPq), Fundação de Amparo à Pesquisa do Estado de Minas Gerais (FAPEMIG) and Merck Sharp \& Dohme. The authors are grateful to Luzia Rosa Resende, José Sérgio Barros de Souza, João Paulo Lopes de Andrade and to all undergraduate students of the Oral Microbiology and Anaerobes Laboratory for technical support.

\section{Kênia Valéria dos Santos, ${ }^{1}$ Jacques Robert Nicoli, ${ }^{1}$ Wanderlany Amancio Martins, ${ }^{1}$ Simone Cristina Coutinho, ${ }^{1}$ Ana Carolina Morais Apolônio, ${ }^{1}$ Cláudio Galuppo Diniz, ${ }^{2}$ Maria Auxiliadora Roque de Carvalho ${ }^{1}$ and Luiz de Macêdo Farias ${ }^{1}$}

${ }^{1}$ Departamento de Microbiologia, Instituto de Ciências Biológicas, Universidade Federal de Minas Gerais, Belo Horizonte, Minas Gerais, Brazil

${ }^{2}$ Departamento de Parasitologia, Microbiologia e Imunologia da Universidade Federal de Juiz de Fora, Minas Gerais, Brazil

Correspondence: Luiz de Macêdo Farias (macedo@icb.ufmg.br)

\section{References}

Chapin-Robertson, K. \& Edberg, S. (1991).

Measurement of antibiotics in human body fluids: techniques and significance. In Antibiotics in Laboratory Medicine, 3rd edn, p. 295-366. Edited by V. Lorian. Baltimore, MD: Williams \& Wilkins.

Dela Pena, A. S., Asperger, W., Kockerling, F., Raz, R., Kafka, R., Warren, B., Shivaprakash, M., Vrijens, F., Giezek, H. \& other authors (2006). Efficacy and safety of ertapenem versus piperacillin-tazobactam for the treatment of intra-abdominal infections requiring surgical intervention. J Gastrointest Surg 10, 567-574.

Freireich, E. J., Gehan, E. A., Rall, D. P., Schmidt, L. H. \& Skipper, H. E. (1966).

Quantitative comparison of toxicity of anticancer agents in mouse, rat, hamster, dog, monkey, and man. Cancer Chemother Rep 50, 219-244.

Goldstein, E. J. C. \& Snydman, D. R. (2004). Intra-abdominal infections: review of the bacteriology, antimicrobial susceptibility and the role of ertapenem in their therapy. J Antimicrob Chemother 53 (Suppl 2), ii29-ii36.

Goldstein, E. J., Citron, D. M. \& Cherubin, C. E. (1991). Comparison of the inoculum effect of cefoxitin and other cephalosporins and of $\beta$-lactamase inhibitors and their penicillin-derived components on the Bacteroides fragilis group. Antimicrob Agents Chemother 35, 1868-1874.

König, C., Simmen, H. P. \& Blaser, J. (1998). Bacterial concentrations in pus and infected peritoneal fluid - implications for bactericidal activity of antibiotics. J Antimicrob Chemother 42, 227-232.

Li, C., Kuti, J. L., Nightingale, C. H., Mansfield, D. L., Dana, A. \& Nicolau, D. P. (2005).

Population pharmacokinetics and pharmacodynamics of piperacillin/tazobactam in patients with complicated intra-abdominal infection. J Antimicrob Chemother 56, 388-395.

Majumdar, A. K., Musson, D. G., Birk, K. L., Kitchen, C. J., Holland, S., McCrea, J., Mistry, G., Hesney, M., Xi, L. \& other authors (2002). Pharmacokinetics of ertapenem in healthy young volunteers. Antimicrob Agents Chemother 46, 3506-3511.

NCCLS (2003). Methods for Dilution Antimicrobial Susceptibility Tests for Bacteria that Grow Aerobically, approved standard, 6th edn, M7-A6. Wayne, PA: National Committee for Clinical Laboratory Standards.

NCCLS (2004). Methods for Antimicrobial Susceptibility Testing for Anaerobic Bacteria, approved standard, 6th edn, M11-A6. Wayne, PA: National Committee for Clinical Laboratory Standards.

Nix, D. E., Majumdar, A. K. \& DiNubile, M. J. (2004). Pharmacokinetics and pharmacodynamics of ertapenem: an overview for clinicians. J Antimicrob Chemother $\mathbf{5 3}$ (Suppl 2), ii23-ii28. 
Santos, K. V., Diniz, C. G., Coutinho, S. C., Apolônio, A. C. M., Sousa-Gaia, L. G., Nicoli, J. R., Farias, L. M. \& Carvalho, M. A. R. (2007). In vitro activity of piperacillin/tazobactam and ertapenem against Bacteroides fragilis and Escherichia coli in pure and mixed cultures. J Med Microbiol 56, 798-802.

Solomkin, J. S., Yellin, A. E., Rotstein, O. D., Christou, N. V., Dellinger, E. P., Tellado, J. M.,
Malafaia, O., Fernandez, A., Choe, K. A. \& other authors (2003). Ertapenem versus piperacillin/ tazobactam in the treatment of complicated intraabdominal infections: results of a doubleblind, randomized comparative phase III trial. Ann Surg 237, 235-245.

Stearne, L. E., van Boxtel, D., Lemmens, N., Goessens, W. H., Mouton, J. W. \& Gyssens, I. C. (2004). Comparative study of the effects of ceftizoxime, piperacillin, and piperacillintazobactam concentrations on antibacterial activity and selection of antibiotic-resistant mutants of Enterobacter cloacae and Bacteroides fragilis in vitro and in vivo in mixed-infection abscesses. Antimicrob Agents Chemother 48, 1688-1698.

Wexler, H. M. (2004). In vitro activity of ertapenem: review of recent studies. J Antimicrob Chemother 53 (Suppl. S2), ii11-ii21. 